\title{
POWER SYSTEM SOLUTION PROVIDED BY FACTS AND HVDC
}

\author{
Pooja Joshi $^{1,}$ Dipa Teraiya ${ }^{2}$, Bhakti Solanki ${ }^{3}$ \\ ${ }^{1,2,3}$ Asst.Prof, Department Of EEE, C.C.E.T Wadhwan, Gujarat, India, \\ puji.joshi@gmail.com,teraiyadipa@gmail.com,gopisandy9@gmail.com
}

\begin{abstract}
Various types of FACTS as well as HVDC have been available for some time. New ones have been developed recently. Their respective benefits are well proven and have been made known. System studies have to be done to make full use of FACTS and HVDC problem solving capabilities. This paper is described the technical and commercial benefits that FACT and HVDC solutions provided and case studies are presented showing how the relevant problem of power system can solved by this paper.
\end{abstract}

Index Terms: FACTS, HVDC, POWER SYSTEM

\section{INTRODUCTION}

Development of electrical power supplies began more than one hundred years ago. This is because the development of electrical power sector historically links to the economic advancement of country. The traditional way to develop the transmission network in order to achieve better linkage between generation and demand was to reinforce the grid, mainly by installing new lines and substations. However, in recent years substantial changes were implemented in the traditional structures of electric power systems throughout the world. The general reason for this is to improve efficiency.

Interconnected power networks operate in different parts and locations or countries that may require different power demand during a certain period of time. These requirements limit the flexibility of the interconnected power network in technical and economical terms. Therefore, establishing a desired power condition at the given points in the above are best achieved using power controllers such as the well known HVDC and FACTS devices.

FACTS and HVDC development over the past two decades are benefited from dramatic advances in power semiconductor technology. As a result of very substantial investments and continued R\&D efforts, several manufacturers have been able to supply FACTS and HVDC systems for all practical needs of the industry. Conventional stability analysis of ac systems incorporating HVDC links or FACTs devices use either steady state or quasi-steady state representations of these non-linear components. While these programs are entirely adequate for representing the dynamic behaviour of generators, they are compromised by their limited representation of non-linear components.

\section{FACTS AND HVDC}

\subsection{FACTS}

Flexible AC Transmission Systems (FACTS) given to the application of power electronics devices to control the power flows and other quantities in power systems.

\subsection{FACTS IEEE Definitions}

AC transmission systems incorporating the power electronicbased and other static controllers to enhance controllability and increase power transfer capability.

\subsection{FACTS Controllers}

A power electronic based system \& other static equipment that provide control of one or more AC transmission parameters.

\subsection{HVDC}

The Power Flow on an HVDC link is Fully Controllable - Fast and Accurate! The operator or automatic controller determines how much power flows via the link and in which direction Irrespective of the interconnected AC system conditions An HVDC Link is asynchronous, The ac voltage and frequency in the two ac networks can be controlled independently of each other, No need for common frequency control.

The HVDC link can be used to improve the dynamic conditions in both of the interconnected ac networks (power system damping) can be controlled independently of $\mathrm{AC}$ system variations or to react to AC system. 


\section{FACTS AND HVDC CO- ORDINATION}

Problem in power system,

- Lack of Investments into the Grids (high Cost Pressure for the Asset Owners due to Deregulation), leading to Bottlenecks in Transmission.

- $\quad$ Need for more Regulatory Works (Rules, Grid code etc.) for the Operation of Transmission Systems and Power Plants in Case of Cascading Events

- Weak Points in the Energy and Demand Side Management EMS, DSM. Solution buys FACTS \& HVDC

- Enhancement of Communication and Monitoring with IT (EMS\& DSM)

- Review of Generator and Load Trip Strategy (Under Voltage and Under Frequency Trip Levels and Times)

- Use of FACTS for Reactive Power, Compensation, Power Flow Control and Prevention of Voltage Collapse

- Active Damping of Power Oscillations with FACTS \& HVDC

- HVDC is a Barrier against cascading events (Voltage Collapse and Frequency decline): * Quebec was not affected!

- Increase of Reserve Capacity (HVDC, new Generations).

\section{HVDC SOLUTION}

In today electricity industry, in view of the liberalisation and increased effects to conserve the environment, HVDC solutions have become more desirable for the following reasons:

Environmental advantages, Economical (cheapest solution), Asynchronous interconnections, Power flow control, benefits to the transmission (stability, power quality etc.). in this paper i used one references paper circuit as show below. Here $\mathrm{i}$ used the MATLAB software. The first circuit is without facts devices.

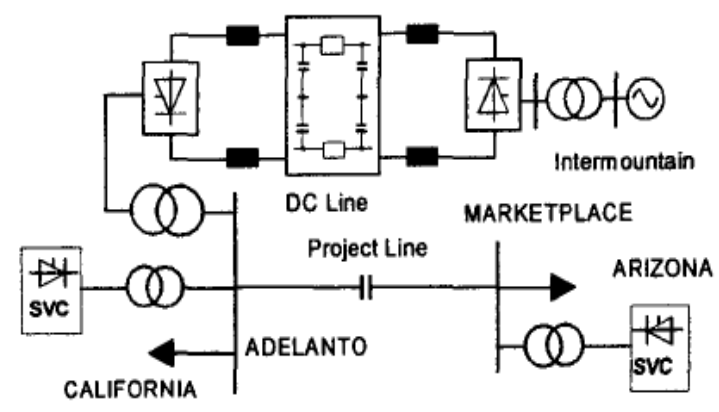

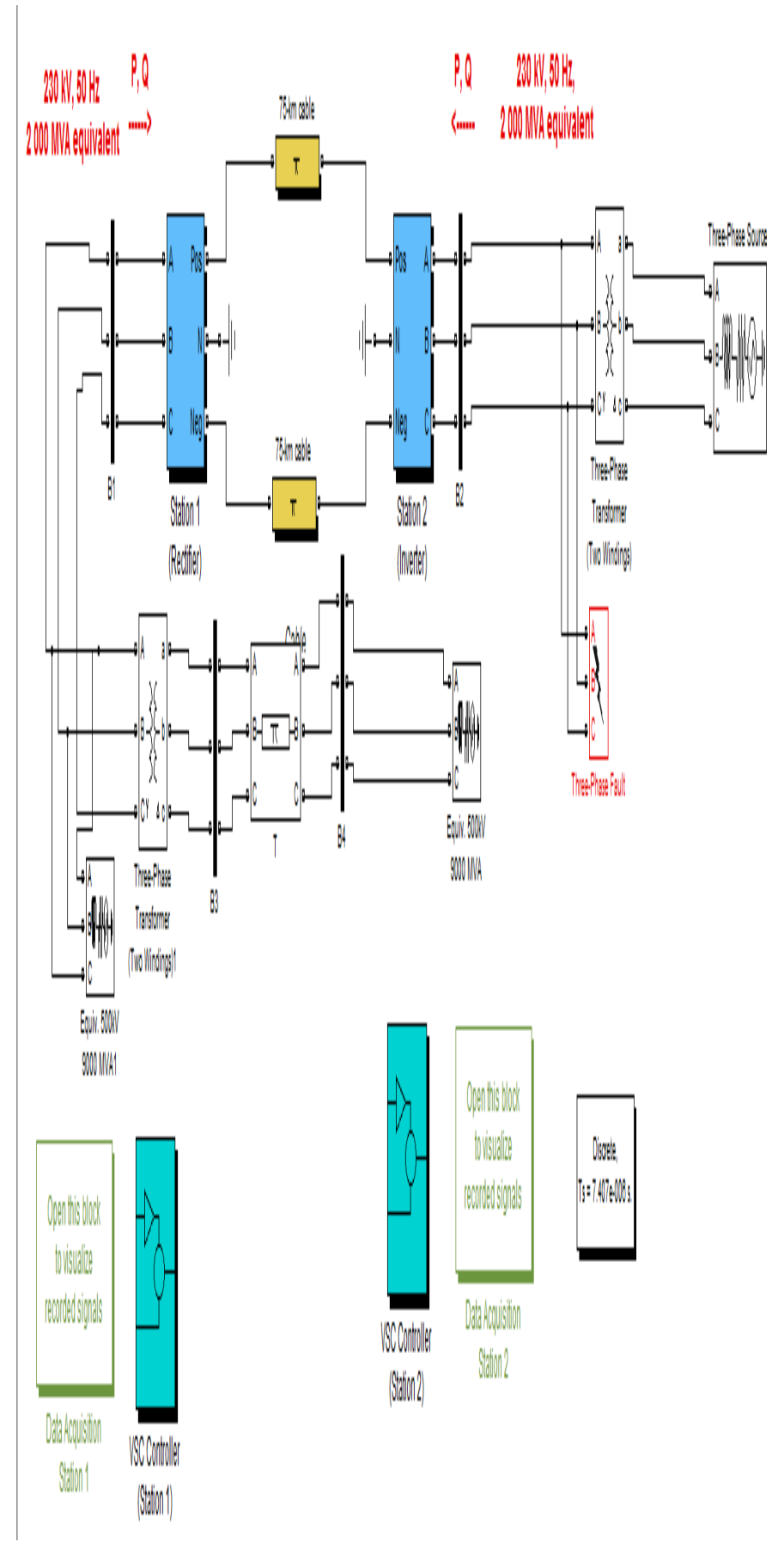

Fig.2 Circuit with reference pa per in MATLAB

Fig.1 Circuit with reference paper 


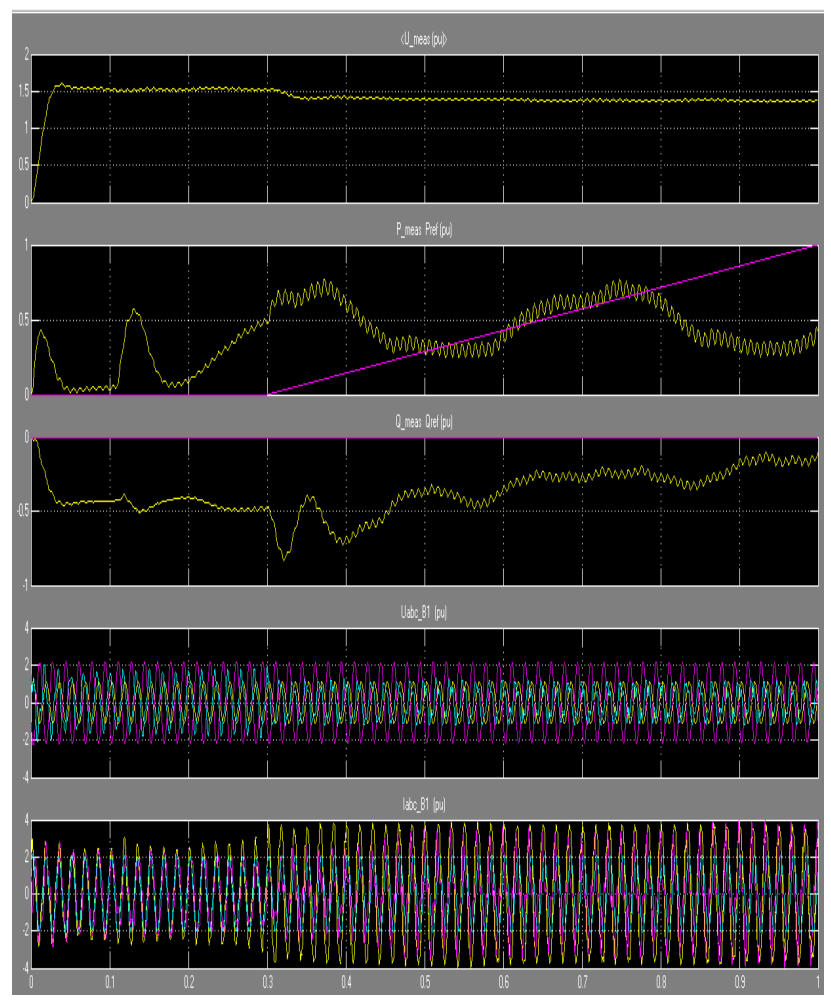

Fig.3 Wave forms of without FACTS HVDC line

We show the comparison of wave forms of the MATLAB software and references paper.
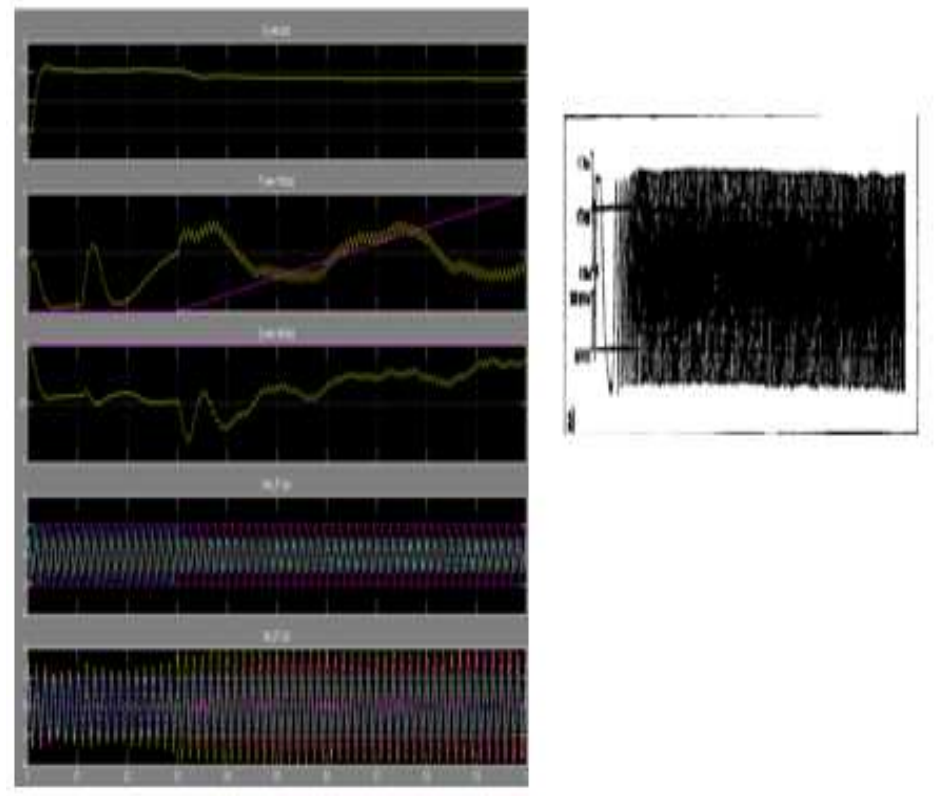

Fig.4. compression wave forms of without facts HVDC line
Here we can shows that result of current wave forms are nearer to same the wave are the system is unstable. Now we can show the HVDC \& FACTS devices.

\section{HVDC \& FACTS SOLUTION}

Use of an SVC close to an HVDC transmission system can improve voltage quality and system stability during and after faults and increase transient stability.

A major $75 \mathrm{kV}$ transmission system extension has been carried out to increase the power transfer capability between two stations. As shown in Fig. 1, the extension includes two series compensated AC lines and two equally rated SVCs, which will operate together with an Existing large HVDC system. Two SVCs of each TCR at 109 MVar and TCS at 94 Mvar have been installed in VSC based HVDC line. The SVCs are designed mainly to improve the transient stability of the transmission system and to reduce voltage dips.

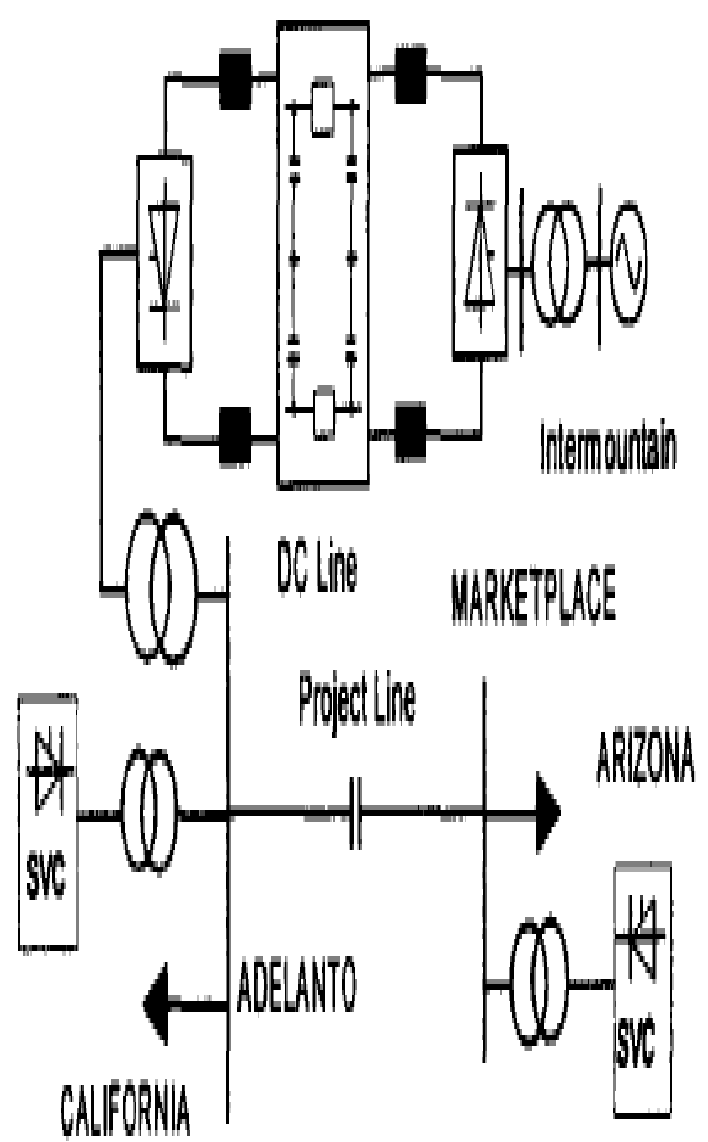




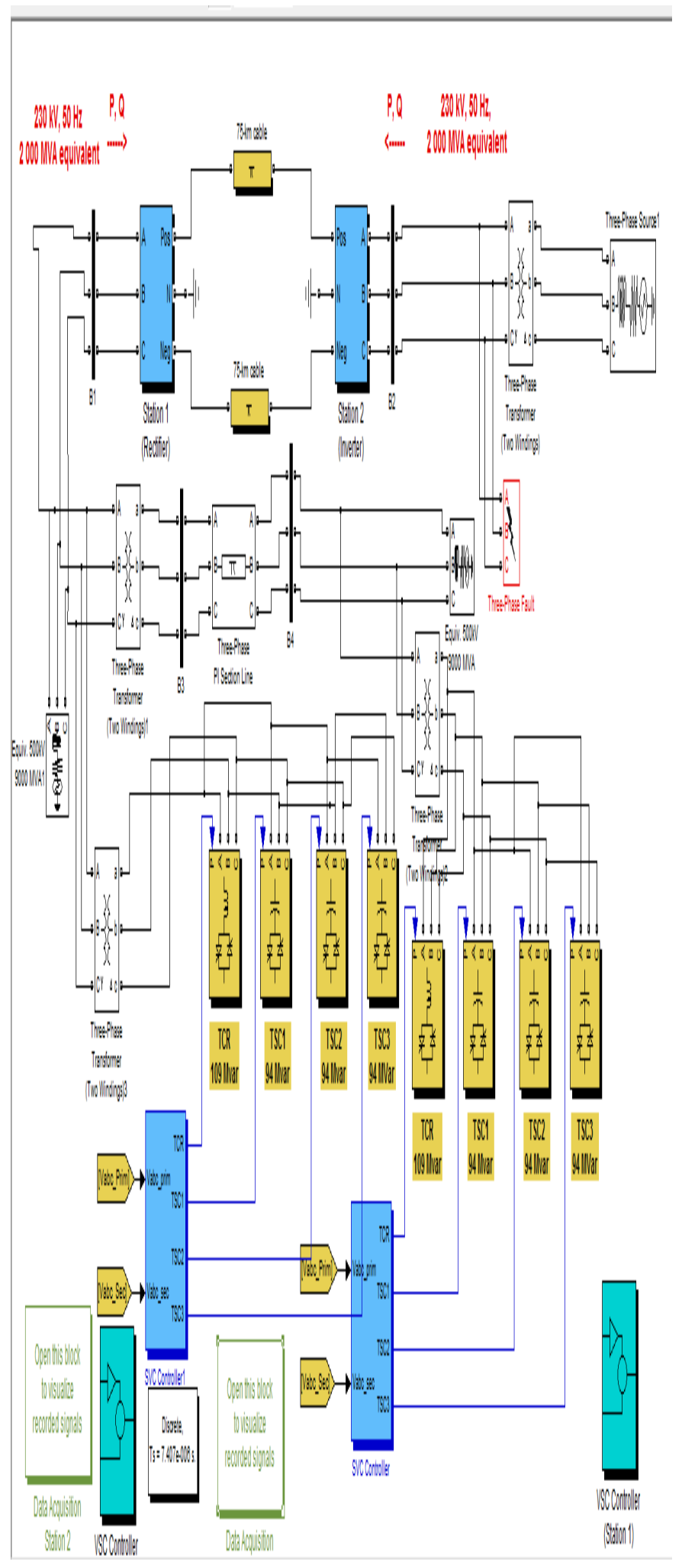

Fig.6.Circuit diagram in MATLAB with facts devices

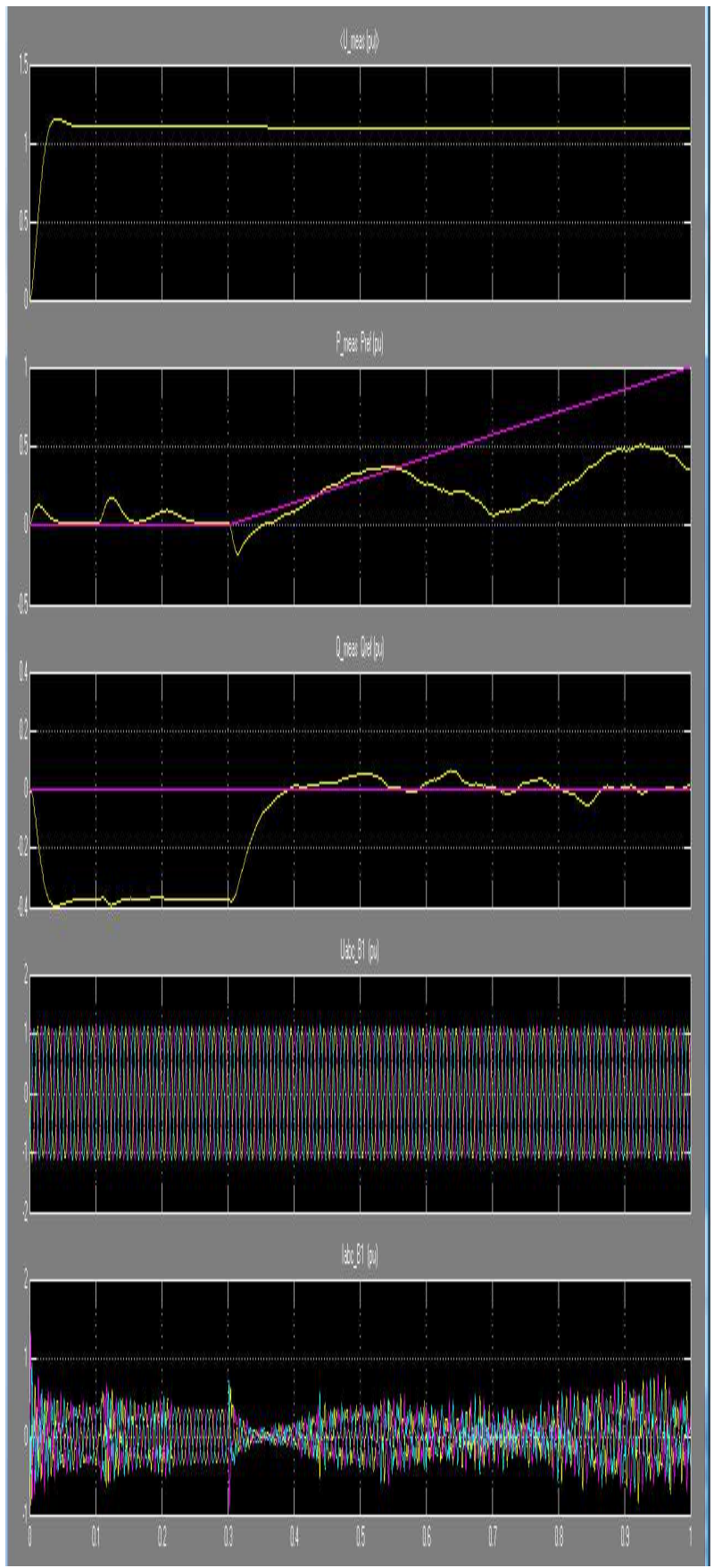

Fig.7 with Fact and Hvdc Wave Forms

The SVC use THYRISTOR switched capacitor in combination with a special control, that provides voltage control and power swing damping facilities only by use of $75 \mathrm{kv}$ bus. Voltage measurement with no need for additional power or frequency measurement 
Now we show the comparison of without facts and with facts. So we can shows that the voltage of without facts is 1.5 P.U while the with facts 1 P.U. and system is stable. $\mathrm{i}$ power is almost same while the reactive power is in facts circuit is 0.01 P.U positive.

\section{Withfactsdevices}

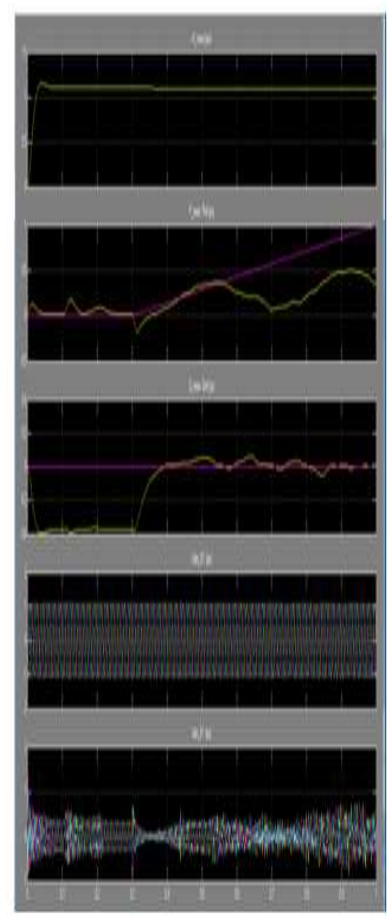

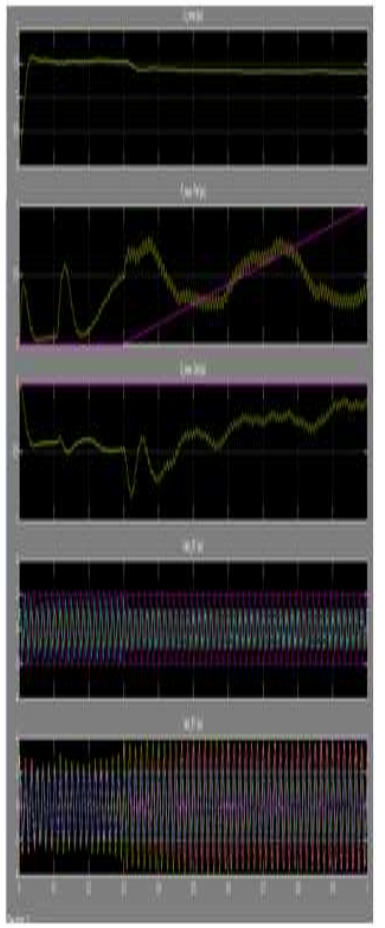

Withoutfactsdevices

Fig.8 Comperision Of with and without Facts Devices

\section{CONCLUSIONS}

Operation requirements on AC and DC transmission systems will strongly focus on reliability and quality of electrical energy. The HVDC and FACTS techniques have been as an advanced means for improving overall power system performance. HVDC and FACTS devices can provide the necessary operation characteristics, and thus efficiently improve the system dynamic performance, especially under weak and very weak system conditions. In this paper, coordinated operations and achievable benefits of the HVDC and THYRISTOR-based FACTS devices have been demonstrated. These schemes are established technology and the required controls can be easily and quickly developed.

\section{ACKNOWLEDGMENTS}

I am very much thanks to my family and my guide and my HASBAD to give me great contrubision in this paper.

\section{REFERENCES}

[1] C Ray, "Transmlsslon Capacity-Risk Management", Proceeding of VI SEPOPE, 1998.

[2] Hmgorarn, N G, "Flexlble AC Transmission", IEEE Spectrum, Vol. 30, No 4, Aprd 1993, pp 40-45.

[3] Larson E V , Clark K, Mwke S. A., Urbanek J., "Charactermhes Rating Conslderatlons of Thynstor Controlled SeriesCompensatinn", IEEE Transactions on Power Delivery, Vol 9, 992-1000, APnl 1994.

[4] 4.Bdlinton, R, Fotuhj-Fmrzabad, M , S O Faned, "Power System Rehability", IEEE Transactions on Power Systems, Vol 15, No 1 February 2000, pp. 410415].

[5] 5. S. R. Sanders, J. M. Noworolski, X. Z. Liu, G. C. Verghese,"Generalized averaging method for power conversioncircuits", IEEE Trans. on Power Electronics, vol. 6, Apr.1991, pp. 251-259.

[6] 6. C. L. Demarco, G. C. Verghese, "Bring phasor dynamics into the power system load flow", 25th North America Power Symposium,1993.

[7] V. Venkatasubramanian, "Tools for dynamic analysis of the general large power system using time-varying phasors",

[8] International Journal on Electric Power and Energy Systems, December 1994,pp. 365-376.

[9] J. Mahdavi, A. Emaadi, M. D. Bellar, et al. "Analysis of power electronic converters using the generalized state2space averaging approach". IEEE Trans. on Circuits System, vol. 48, Aug.1997, pp.767-770.

\section{BIOGRAPHIES}

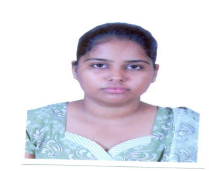

Asst Prof Pooja Joshi EEE Department CCET Wadhwan B.E.(Electrical) M.E.(Electrical)

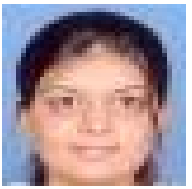

Asst Prof Dipa Teraiya EEE Department CET Wadhwan B.E.(Power electronics) M.E.(Electrical)

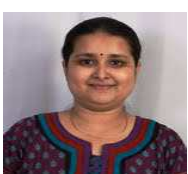

Asst Prof Bhakti Solanki EEE Department CCET Wadhwan B.E.(Electrical) M.E.(Electrical) 